\title{
Female Physicians Leading Health Care in the Arab World
}

\author{
Salman Al Sabah ${ }^{\mathrm{a}}$ Fajer AlHamdan $^{\mathrm{a}} \quad$ Iman Qadhi $^{\mathrm{a}} \quad$ Sameera Shuaibi $^{\mathrm{a}}$ \\ Shaden Younes ${ }^{\text {a }}$ Eliana Al Haddad ${ }^{b}$ \\ ${ }^{a}$ Department of Surgery, Faculty of Medicine, Kuwait University, Kuwait City, Kuwait; ${ }^{b}$ Department of Surgery, \\ Faculty of Medicine, Al Amiri Hospital, Kuwait City, Kuwait
}

\section{Significance of the Study}

- The number of women in the medical community has been shown to be on a rise, with women taking up leadership positions in hospitals all over the world. However, the Arab world, given its more conservative nature, was thought to have been lagging in that trend. However, it is now seen that females currently occupy more leadership positions in government hospitals in Kuwait than males.

\section{Keywords}

Epidemiology $\cdot$ Health informatics $\cdot$ Kuwait

\begin{abstract}
Background and Objectives: A global trend in female leadership roles in the medical profession is on the rise, and females have been taking up leadership roles in varying and increasing levels. This study aims to identify changes in trends in the medical field in terms of gender in the last decade in Kuwait. Methods: A case study was conducted, in which data on leadership positions in Kuwait's government hospitals were obtained from hospital registries. Demographic data about female to male physicians were collected from statistics published by the Department of Manpower, Statistics and Planning of Kuwait's Ministry of Health. In addition, statistics on medical graduates were obtained from the Faculty of Medicine (FOM), Kuwait University (KU). $\boldsymbol{R e}$ sults: In general, every government hospital in Kuwait has experienced an increase in leadership roles among females;
\end{abstract}

in 2008, among all leadership positions in Kuwait's general hospitals, males occupied a majority of positions (60\%); whereas in 2016, the male to female ratio was 1:1. The most change in gender trends was witnessed at Mubarak Al-Kabeer Hospital, where female leaders went from 38\% in 2008 to $73 \%$ in 2016 . The specialties that have the highest number of females in leadership positions across all hospitals from 2008 to 2016 were nuclear medicine, radiology, and laboratory medicine. In KU's FOM, female graduates outweighed male graduates, except in 2005-2006, where females reached a minimum of $48 \%$. The number of female physicians has also increased from its lowest of $31 \%$ of the total number of physicians in 2004-2006, to 37\% in 2015. Conclusion: While women make up more than half of medical graduates in Kuwait at present, significant barriers had restricted their entry into formal medical leadership roles in the past. However, it is now seen that females currently occupy more leadership positions in government hospitals in Kuwait.

(c) 2019 The Author(s)

Published by S. Karger AG, Basel

\begin{tabular}{|c|c|c|}
\hline KARGER & $\begin{array}{l}\text { (c) } 2019 \text { The Author(s) } \\
\text { Published by S. Karger AG, Basel }\end{array}$ & $\begin{array}{l}\text { Karger } \\
\text { Open access }\end{array}$ \\
\hline $\begin{array}{l}\text { E-Mail k } \\
\text { www.ka }\end{array}$ & $\begin{array}{l}\text { This is an Open Access article licensed } \\
\text { Attribution-NonCommercial- } 4.0 \text { Inte } \\
\text { (http://www.karger.com/Services/Ope } \\
\text { the online version of the article only. } L \\
\text { mercial purposes requires written per }\end{array}$ & $\begin{array}{l}\text { the Creative Commons } \\
\text { al License (CC BY-NC) } \\
\text { sLicense), applicable to } \\
\text { d distribution for com- }\end{array}$ \\
\hline
\end{tabular}

Salman Al Sabah

Department of Surgery

Faculty of Medicine, Kuwait University

Kuwait City 20269 (Kuwait)

E-Mail salman.k.alsabah@gmail.com 
Fig. 1. Male and female percentage leadership positions trends with time in all hospitals.

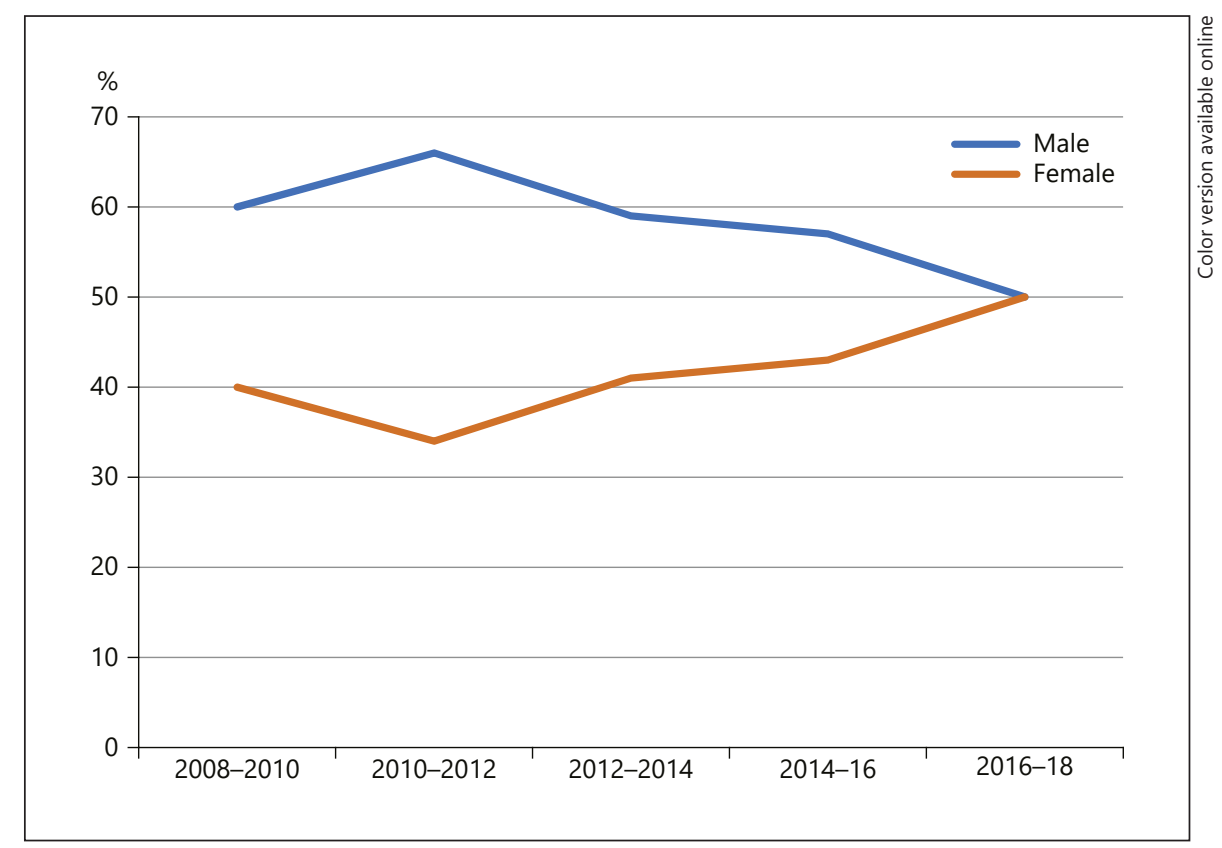

\section{Introduction}

The role of women in the 21st century has drastically evolved, from being restricted to their domestic duties to reaching leadership positions in numerous professional fields. Major improvements have been seen in the role of women in the Arab world, where now, not only are female medical graduates outnumbering males but are also competing with them for leadership positions in health-care institutions.

For example, in the United States, between 1970 and 2005 , women's share of seats in medical schools increased from 11 to $48.9 \%$ [1]. During the same period, women's numerical representation among practicing physicians increased nearly nine-fold, from 25,000 in 1970 to 225,000 in 2002 [2]. This was seen to be paralleled in Kuwait, where the percentage of female physicians was $31 \%$ in the year 2004 compared to $37 \%$ in 2015 [3].

In Kuwait, the patriarchal society failed to recognize women's contributions to the country, or their constitutional rights until 2005, and in 2009 women managed to send female representatives to the National Assembly for the first time [4]. This was also mirrored by leadership roles of female physicians in Kuwait in the present decade, between the years 2008 and 2018. In addition, it was further reflected in the admission policy at the Faculty of Medicine (FOM) in Kuwait University (KU). The previous policy was biased toward males, whereby females who had higher grade point averages were not accepted due to the 50/50 allocation of seats based on gender. However, this was abolished in 2011 to eventually comply with Article 29 of the Kuwaiti Constitution that voices gender equality.

The purpose of this study was to shed light on the evolution of female leadership roles in healthcare institutions of Kuwait in the present decade. The aim was, firstly, to identify the change in female leadership trends in the last 10 years; secondly, to identify the transition of the population of female graduates between the years 2000 and 2016; thirdly, to identify the percentage of females in leadership positions in each medical specialty, and finally, to identify the percentage of females among the total number of physicians in Kuwait between the years 2004 and 2016.

\section{Methods}

Data for this case study were collected from August to December 2016. The figures illustrating leadership positions in all governmental hospitals in Kuwait were collected from hospital registers of previous and current heads of departments. The hospitals included were Mubarak Al-Kabeer Hospital, Al-Adan, Farwaniya, Amiri, and Jahra. The aim was to capture the transition in leadership roles among the heads of departments according to gender in Kuwait's governmental hospitals. The specialties that were studied included internal medicine, surgery, pediatrics, emergency medicine, orthopedics, dermatology, radiology, nuclear medicine, laboratory medicine, physiotherapy, gynecology, anesthesiology, and ICU. We investigated the number of females in the leadership positions in each of these specialties. In addition to the former, some specialties were specific to certain hospitals and not others; there- 
Fig. 2. Male and female percentage leadership positions trends with time in Mubarak hospital.

Fig. 3. Male and female percentage leadership positions trends with time in Adan hospital.
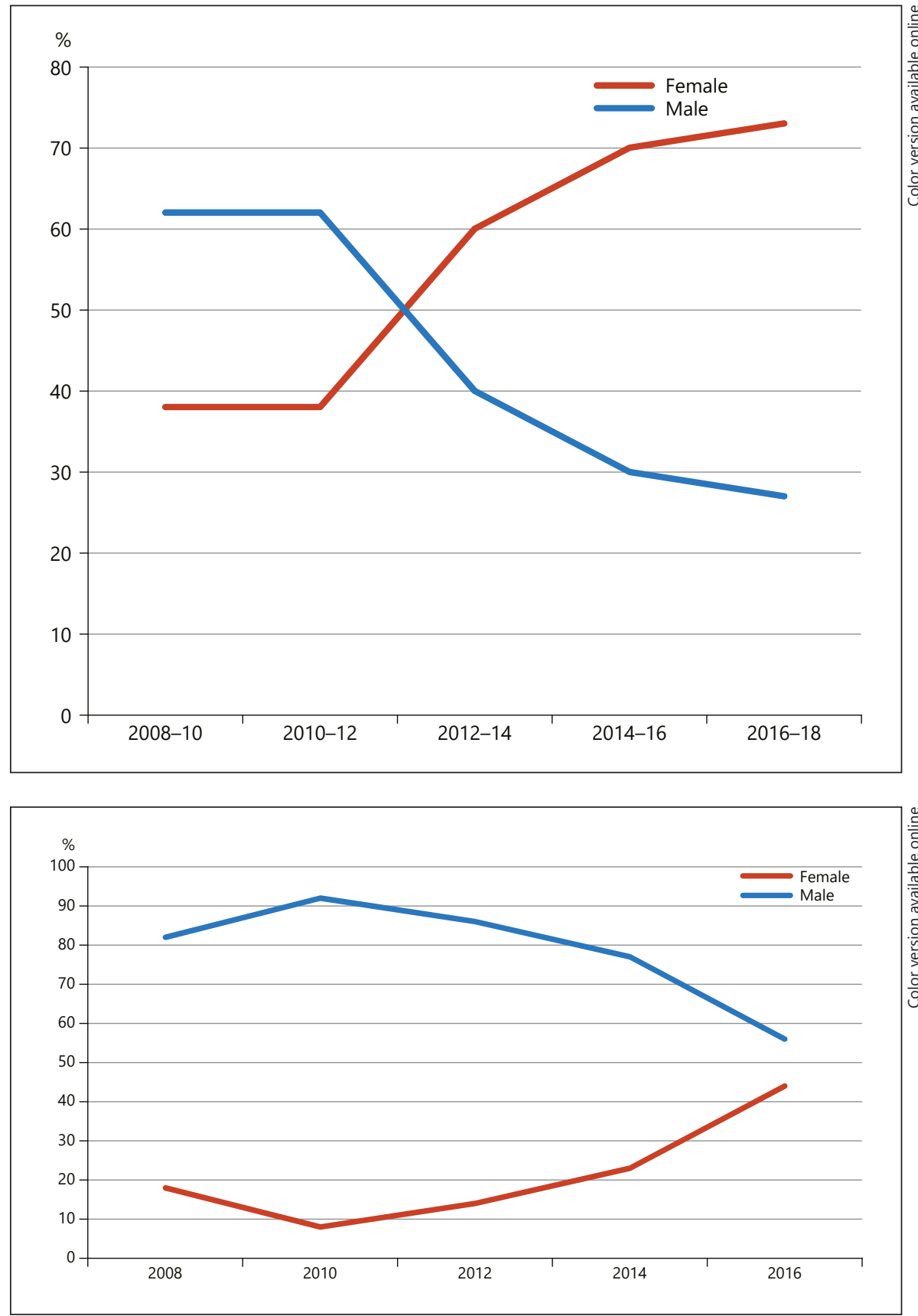

fore, every hospital had its own total number of specialties, and trends were studied based on each as an entity of its own between the years 2008 and 2018. In doing so, data about the heads/chairman of each department in every hospital were obtained in order to observe the transition over these years in terms of gender.

Moreover, demographic data were collected about the population of female to male physicians from statistics published by the Department of Manpower, Statistics and Planning of the Ministry of Health during 2004-2015 [3]. In addition, statistics concerning the number of medical graduates yearly from 2000 to 2016 were obtained from the administrative office of the FOM in KU.

Female Physicians in Kuwait

\section{Results}

In general, every hospital showed an increasing trend in female leadership positions with time; more female physicians had taken up the roles of heads of specialties with the years as shown in Figure 1. With respect to Mubarak Al-Kabeer Hospital, between the years 2008 and 2012 , the percentage of female to male heads of departments stagnated at 38 and $62 \%$, respectively. From then 
Fig. 4. Male and female percentage leadership positions trends with time in Amiri hospital.

Fig. 5. Male and female percentage leadership positions trends with time in Farwaniya hospital.
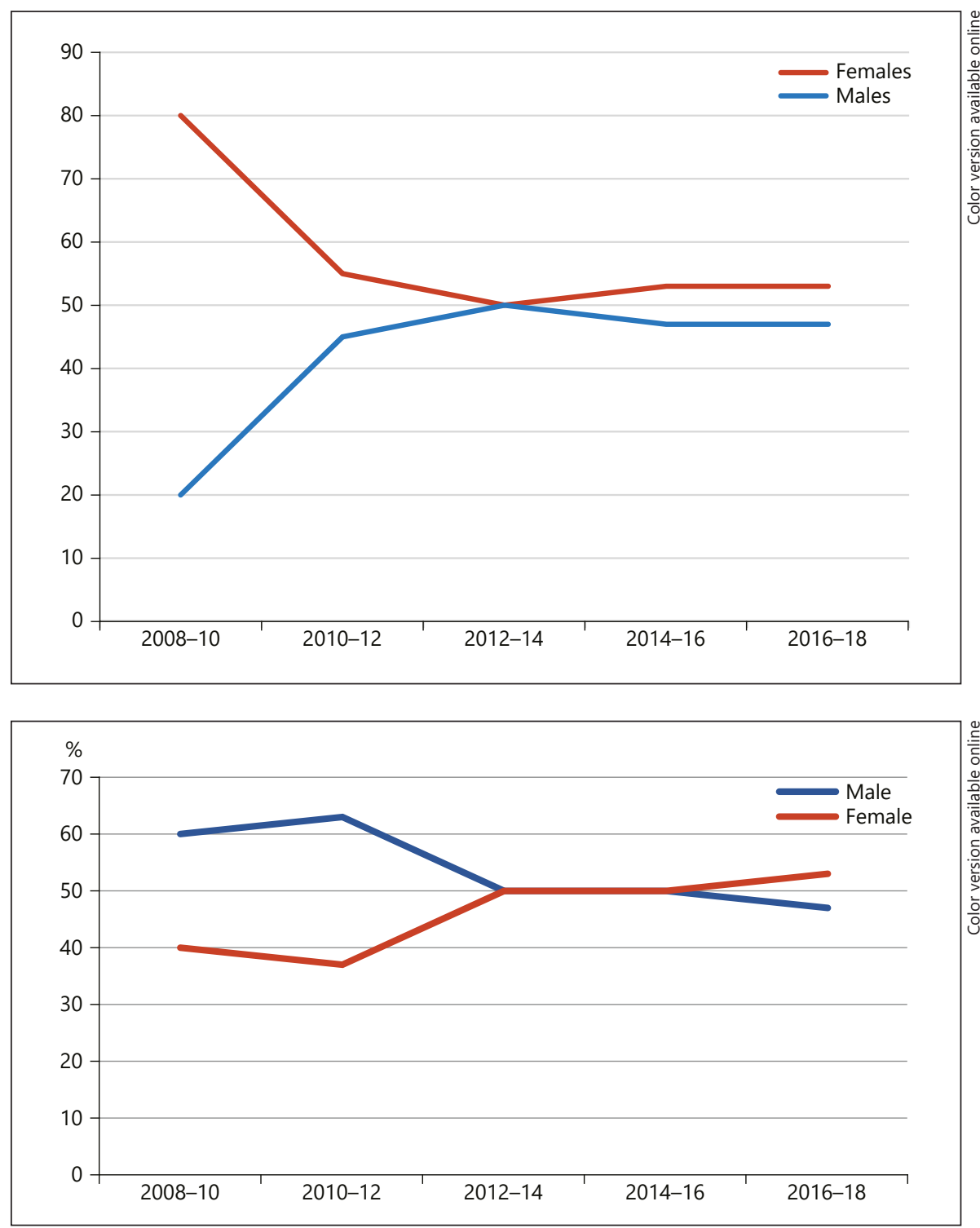

on, the number of females was on a rise, reaching an alltime high of 73\% females in the years 2016-2018 (Fig. 2). Similarly, Adan Hospital showed an increase in trends of the number of female leaders after the year 2010, where it had reached its lowest percentage of female leaders at $8 \%$, followed by an increase to $44 \%$ in 2016 (Fig. 3). Even though the percentage of female leaders in Amiri hospital was decreasing sharply from 2008, where the percentage of female leaders was $80 \%$, it picked up after 2012 , reaching 50\% in the years 2012-2014. Since then, the numbers rose again to reach $54.5 \%$ in 2016 (Fig. 4). Given this pattern, females still outnumber males in Amiri hospital. Farwaniya Hospital on the other hand witnessed a steady upsurge from 2008, where female heads of specialties rep- resented $40 \%$ of all leadership positions, to $53 \%$ in 2016 (Fig. 5). Lastly, female leaders in Jahra Hospital consistently rose from $18 \%$ in 2008 to $43 \%$ in 2016 (Fig. 6).

Another objective was to study the trend in the number of female graduates from the FOM in KU from the years 2000 to 2016 . It was observed that female graduates outweighed male graduates except in the years 20052006 , where females reached a minimum of $48 \%$. Ever since then, the trend has been fluctuating between 51 and $68 \%$ in the years 2015-2016, which was the highest recorded number of female graduates in the history of Kuwait since the establishment of the FOM in 1973 (Fig. 7).

Yet another objective of this study was to shed light on the percentage of female heads per specialty and not just 
Fig. 6. Male and female percentage leadership positions trends with time in Jahra hospital.
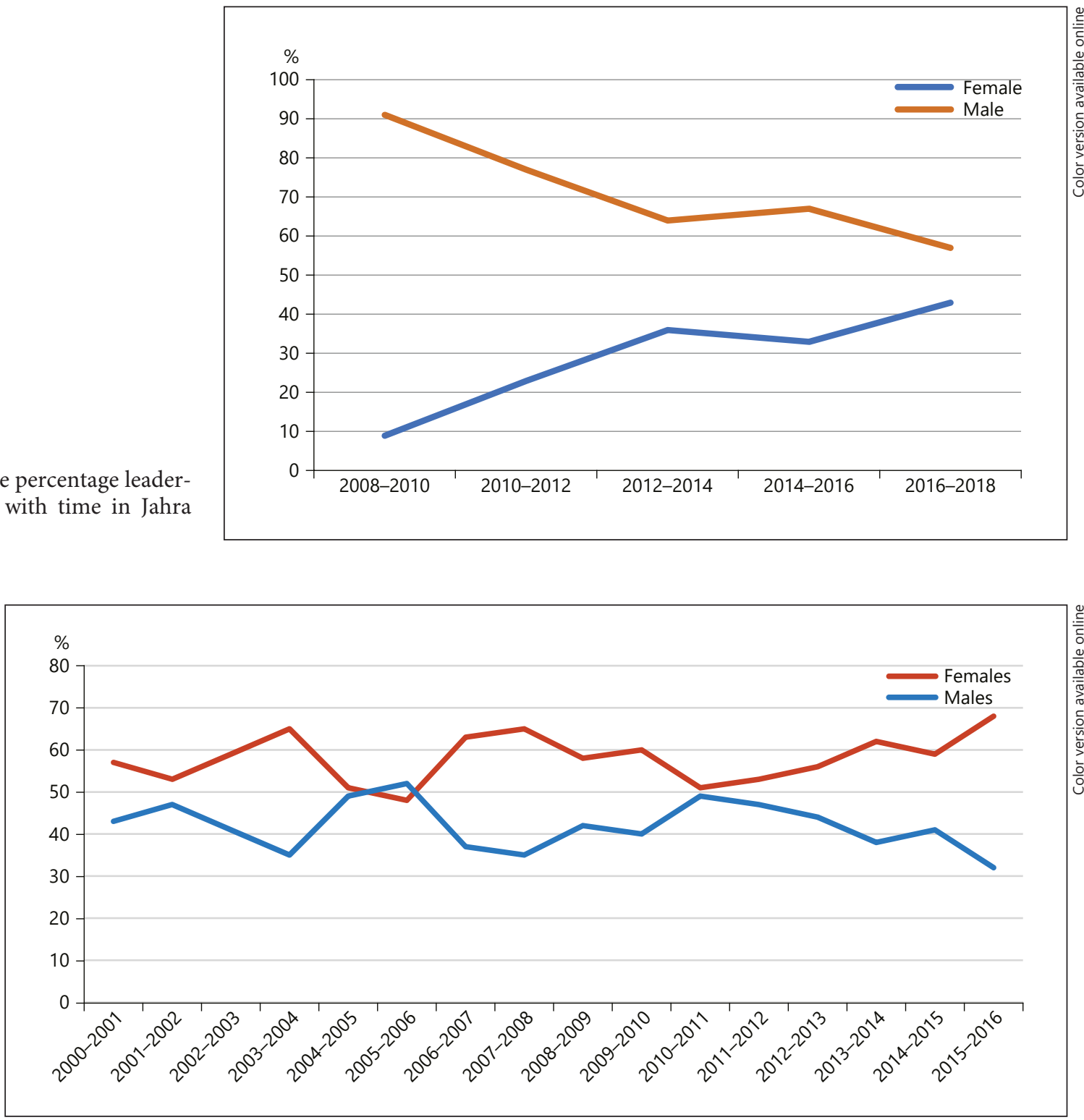

Fig. 7. Percentage of graduates from KU Medical School in terms of gender.

per hospital. As seen in Figure 8, the specialties that harbored the highest number of female leaders across all 5 hospitals between the years 2008 and 2016 are nuclear medicine, radiology, and laboratory medicine. In contrast, the lowest numbers were observed to be in general surgery and emergency medicine and the least of all was seen in orthopedics. However, emergency medicine is experiencing an increase in the number of female heads during the past few years. Female heads of internal medicine have been constant at $40 \%$ during the same period, paralleled by physiotherapy at $40 \%$. Increasing trends were noted in anesthesiology, dermatology, and radiology female heads. On the other hand, decreasing trends were seen in pediatrics and gynecology.

Finally, we also compared the number of female physicians to male physicians in the government hospitals and clinics of Kuwait from the years 2004 to 2016. This is depicted in Figure 9, where an increase in the total number of female physicians is observed from its lowest in 20042006 , constituting $31 \%$ of the total number of physicians, 


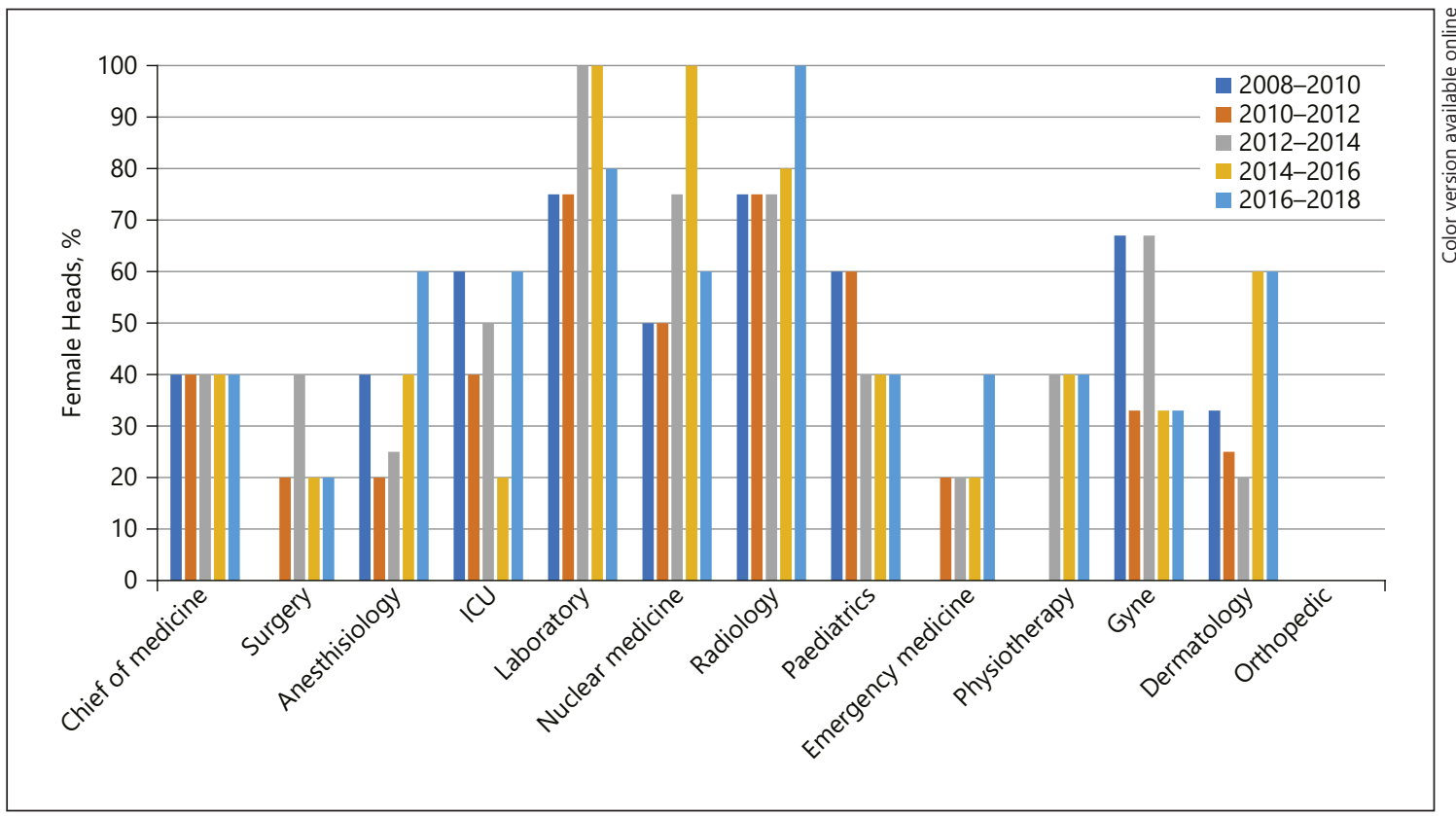

Fig. 8. Percentage of female heads in each specialty with time.

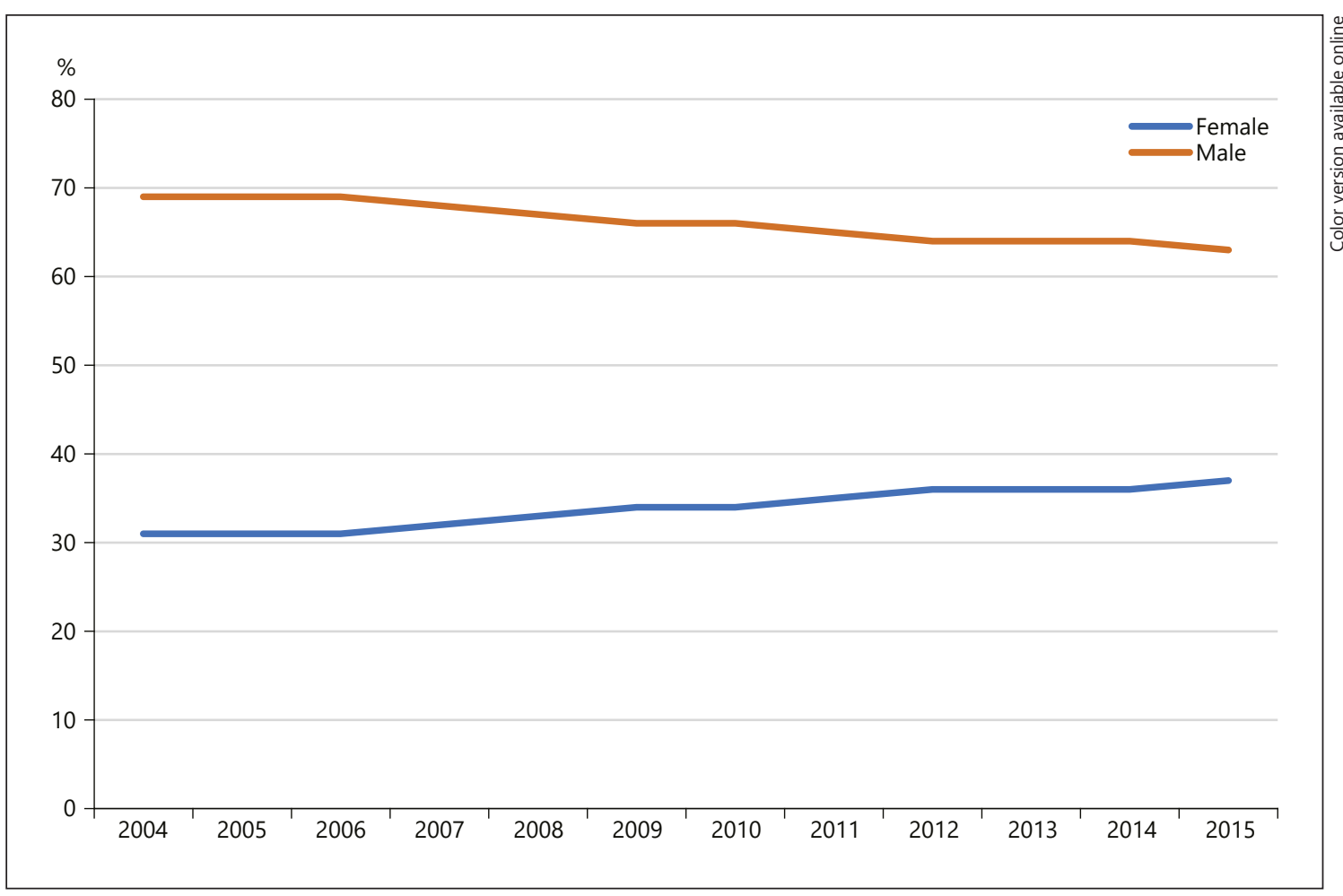

Fig. 9. Percentage of physicians according to gender. 
to $37 \%$ in 2015 . Even though the difference is not substantial, the gap between the number of male and female physicians is narrowing.

\section{Discussion}

This study aimed to discover the magnitude of the transition in gender roles within the medical field in $\mathrm{Ku}$ wait. This is the first time a study of this nature has been conducted in Kuwait. As expected, the worldwide trend was paralleled in Kuwait; more leadership positions were seen to be occupied by female physicians.

Furthermore, an increased percentage of the graduating class of KU's FOM annually was females, indicating that the number of seats being taken up by females is increasing. A study in the United Kingdom suggested that one of the reasons for the increase in the number of female physicians is that they are reaching the age at which leadership opportunities present themselves (around the age of 50) [5].

Overall, there is a consensus that every government hospital witnessed an increase in the number of female leaders in the past decade. However, some hospitals experienced a greater shift than others, with some harboring more female leaders than males. On the other hand, those that did not follow in the same manner are still experiencing a rise in the number of femaleleaders. Mubarak and Amiri hospitals were seen to be dominated by female leaders. This may be due to their geographical locations mainly comprised of a more educated population with a higher socioeconomic status, living in the city center or in urban areas; Adan and Jahra hospitals are located in areas revolving around older traditions and culture that are more empowering of males and restrictive of females; therefore, it is more understandable why female leaders are still seen to be outnumbered by their male counterparts. The same cannot be said about Farwaniya hospital; even though it accommodates a population of citizens who are governed by their traditions, it is composed of a wider diversity of noncitizen residents who do not comply with the traditional regime of Kuwait [6]. As a result, it was seen that females dominate the leadership positions, specifically after the year 2014 .

After 2011, KU's FOM implemented a regulation that favors personal achievements regardless of gender, rather than having a 50-50 allocation of seats based on gender. Female medical students at that time tended to score higher than males. Therefore, after that law was passed, it was seen that more females occupied seats in the FOM.

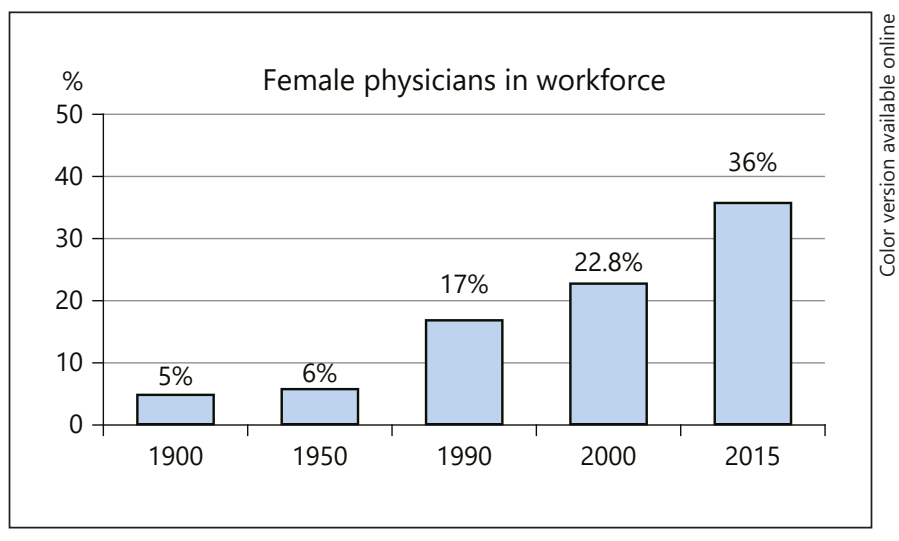

Fig. 10. Percentage of female physicians in the workforce with time.

The amendment to the admission policy in accordance with the constitution of Kuwait promotes gender equality. The effect of this amendment has not been seen yet as the students that the law was applied to are yet to graduate. This might explain why there has been a minimal increase in the number of female physicians. Another reason for why female physicians are still heavily outnumbered by their male counterparts could be due to the fact that a majority of health-care professionals are non-nationals (61.9\%), and females comprise only $29.7 \%$ [3].

Another focus of this study was to identify the specialties that recruit more female leaders compared to other specialties. Radiology, nuclear medicine, and laboratory medicine had the highest numbers, while orthopedics, general surgery, and emergency medicine had the lowest numbers. This is somewhat consistent with the United States where women were substantially underrepresented among residents in neurosurgery, orthopedics, urology, otolaryngology, general surgery, and radiology [7]. On the other hand, there is a decreasing trend in the number of female heads in pediatrics and gynecology. This may be attributed to the change in the perception of gender roles between physicians as the world strives to move toward gender equality. Further work needs to be done to explore strategies that may maximize participation rates, particularly during the childrearing years, and to enable greater work-life balance, for both men and women doctors.

The field of surgery is still dominated by males, with no significant rise in the number of female heads of departments in Kuwait. This may be due to the limited number of females choosing it as a career. This was seen in a study in the United States, where the number of wom- 


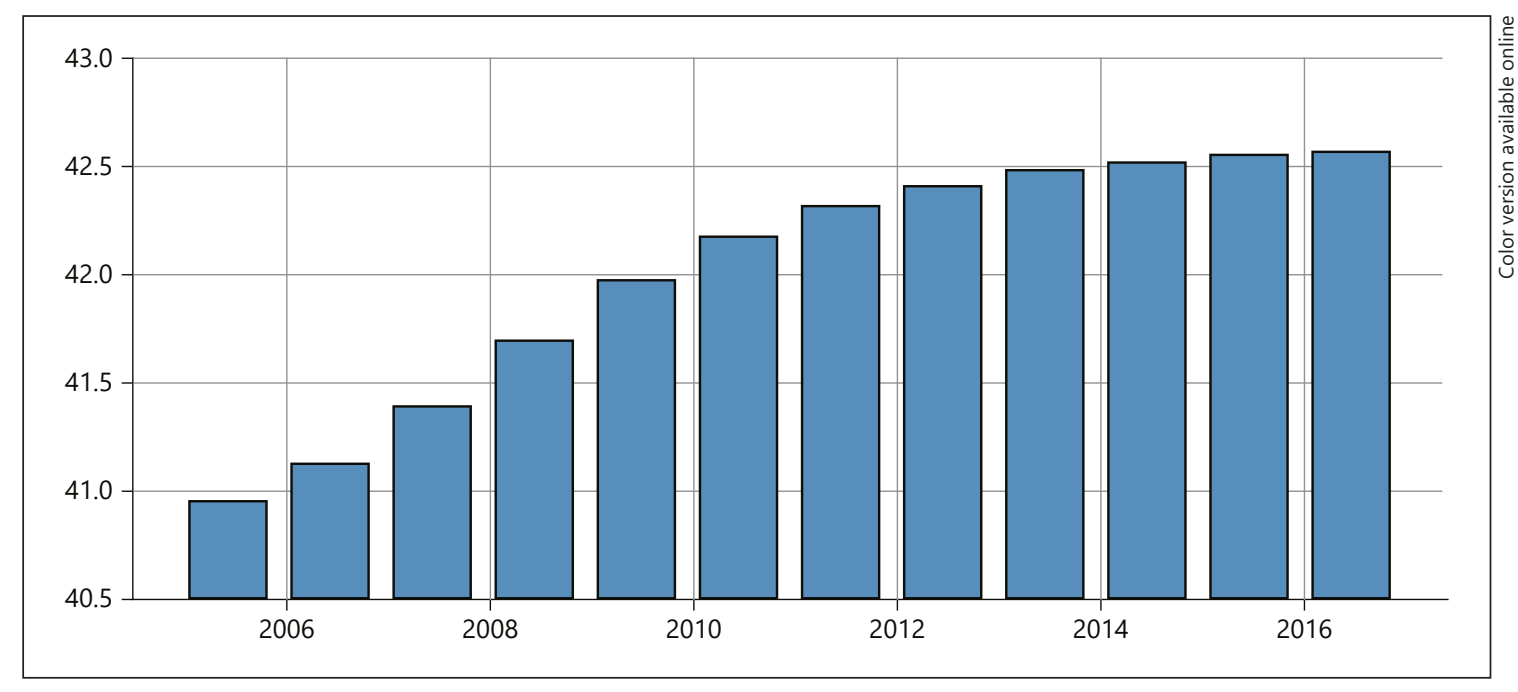

Fig. 11. Female population in Kuwait (as a percentage of the total).

en residents in surgery including obstetrics and gynecology do not exceed that of men, however, still experiencing an increase. In 2001, it was found that females comprised $2 \%$, which rose to $14 \%$ in 2011 [8]. Moreover, another study in the United States reported that the number of female medical students and residents in general surgery has jumped from $24 \%$ in 2001 to $37 \%$ in 2011 [9].

Surgery, including obstetrics and gynecology, are 2 of the most demanding fields in medicine. It was determined by one study that one of the barriers to the advancement of women physicians is the extensive demands of the household $[10,11]$. A Norwegian study concluded that it is not the lack of competence of females in the surgical fields, rather their difficulty to balance work load, which includes heavy on-call duties, with childcare and familial responsibilities. It was found that many females opt for surgery just as much as males; however, they fail to reach to senior levels [12]. Furthermore, female physicians on average receive less in terms of salary than male physicians as seen from previous studies conducted, which could explain why females opt for specialties that will not interfere with their social and family lives $[13,14]$. However, this is not the case in Kuwait given that equal wages have existed for both genders that are at the same level in their career throughout the history of the country.

Orthopedics among all surgical specialties seems to have the least number of women. This is seen in Kuwait as well as internationally. For example, in the United States, a study conducted among the American Association of Medical Colleges reported that orthopedics has the lowest percentage of women compared with all other surgical specialties [15]. A study concluded that extended working hours, physical demands, as well as practicing in a male-dominated field hindered their interest in orthopedics [16].

It is certainly advantageous to have more females recruited as it was found that among medicare patients the mortality rates, readmissions, and comorbidities were far less among female than male internists at the same hospitals [17]. The National Health Service of the United Kingdom emphasized the need for more female physicians in order to solve some of the current recruitment deficits in the number of general practitioners and the field of psychiatry [5].

Finally, one of the outcomes of the research was to demonstrate the shrinkage of the gap between the population of male and female physicians in Kuwait. According to the Association of American Medical Colleges, the same could be said about female physicians in the United States who have experienced a similar rise in the medical work force in the last century (Fig. 10) [18]. As Kuwait moves away from restricting cultural and traditional norms that have been restraining females, more women are aspiring to become physicians. This could also be linked to the implementation of the law in 2011 that opposed gender bias in the medical school in Kuwait. This can partly be attributed to the increasing acceptance by Kuwait's society of the involvement of women in the workforce backed by agendas put forward by the Kuwaiti government, which has seen greatest achievement in 
post-war Kuwait where women's issues were on top of the national agenda. Their participation in liberation efforts after the Gulf war was recognized and the government sought to reward them [4]. Thus, a dramatic influx of women in the workforce was noted ever since then. It was met with a parallel societal outlook in terms of women contributing to the workforce. The increase in the female population in Kuwait in the last 10 years has not been different, and therefore may not attribute to the substantial increase in the number of female physicians in Kuwait (Fig. 11) [19].

This report does have some limitations. The demographic data collected from statistics published by the Department of Manpower, Statistic, and Planning of the Ministry of Health annually from the years 2004 to 2015 dated back only to 2004. It would have been useful to have data from pre-Gulf War Kuwait as one could then analyze with further depth the true pattern in the evolution of the role of women in the workforce, specifically, the medical field. Published data on heads of specialties in government hospitals did not include the same departments for each hospital. Instead, some specialties were included in some hospitals and omitted in others. In addition, limited worldwide data were available to compare our study.

\section{Conclusions}

While females constitute more than half of medical graduates in Kuwait nowadays, significant barriers had restricted their entry into formal medical leadership roles in the past. However, our study proved that Kuwait is experiencing a transition in the role of female physicians, whereby a higher number of graduates from Kuwait's medical school was shown to be female. Also observed was an increase in the total number of female physicians in Kuwait. Additionally, all the government hospitals in Kuwait are experiencing a rise in the leadership positions held by female doctors. One can safely predict that the transition will only surge further than what has currently been observed, with more females taking up leadership positions in the future.

\section{References}

1 Association of American Medical Colleges. http://www.aamc.org (accessed January 2017).

2 Boulis AK, Jacobs JA. The changing face of medicine: women doctors and the evolution of health care in America. New York: Cornell University Press; 2008. p. 2.

3 Ministry of Health. Manpower Statistics. Kuwait: $\mathrm{MOH} ; 2015$.

4 Olimat MS. Women and the Kuwaiti national assembly. J Int Womens Stud. 2011;12:76-95.

5 Dacre J. We need female doctors at all levels and in all specialties. BMJ. 2012 Apr;344 apr04 1:e2325.

6 The Public Authority for Civil Information. http://stat.paci.gov.kw/englishreports/\#Data TabPlace:view1ArcGISRegionMap (accessed May 2017)

7 Jagsi R, Griffith KA, DeCastro RA, Ubel P. Sex, role models, and specialty choices among graduates of US medical schools in 20062008. J Am Coll Surg. 2014 Mar;218(3):34552.
8 Wirtzfeld DA. The history of women in surgery. Can J Surg. 2009 Aug;52(4):317-20.

9 Weiss A, Lee KC, Tapia V, Chang D, Freischlag J, Blair SL, et al. Equity in surgical leadership for women: more work to do. Am J Surg. 2014 Sep;208(3):494-8.

10 Wietsma AC. Barriers to success for female physicians in academic medicine. J Community Hosp Intern Med Perspect. 2014 Jul;4(3): 24665.

11 Troppmann KM, Palis BE, Goodnight JE Jr, Ho HS, Troppmann C. Women surgeons in the new millennium. Arch Surg. 2009 Jul; 144(7):635-42.

12 Gjerberg E. Gender similarities in doctors' preferences-and gender differences in final specialisation. Soc Sci Med. 2002 Feb;54(4): 591-605.

13 Jagsi R, Griffith KA, Stewart A, Sambuco D, DeCastro R, Ubel PA. Gender differences in the salaries of physician researchers. JAMA. 2012 Jun;307(22):2410-7.

14 Jena $A B$, Olenski AR, Blumenthal DM. Sex Differences in Physician Salary in US Public Medical Schools. JAMA Intern Med. 2016 Sep;176(9):1294-304.
15 Blakemore LC, Hall JM, Biermann JS. Women in surgical residency training programs. J Bone Joint Surg Am. 2003 Dec;85-A(12): 2477-80

16 Baldwin K, Namdari S, Bowers A, Keenan MA, Levin LS, Ahn J. Factors affecting interest in orthopedics among female medical students: a prospective analysis. Orthopedics. 2011 Dec;34(12):e919-32.

17 Tsugawa Y, Jena AB, Figueroa JF, Orav EJ, Blumenthal DM, Jha AK. Comparison of Hospital Mortality and Readmission Rates for Medicare Patients Treated by Male vs Female Physicians. JAMA Intern Med. 2017 Feb; 177(2):206-13.

18 Staff Care. https://www.amnhealthcare.com/ uploadedFiles/MainSite/Content/Staffing Recruitment/Staffcare-WP-Women $\% 20$ in\%20Med.pdf (accessed August 2018).

19 Trading Economics. https://www.tradingeconomics.com/Kuwait/population-femalepercent-of-total-wb-data.htm (accessed August 2018) 